\title{
First year medical students' and standard precautions: The need for change
}

\author{
Banerjee Ankita, Mohapatra Ipsa \\ Department of Community Medicine, Kalinga Institute of Medical Sciences, KIIT University, Bhubaneswar, Odisha, 751024, India
}

\section{A R T I C L E I N F O}

\section{Keywords:}

Standard precautions (SPs)

Competency based medical education(CBME) Medical students

Parents

\begin{abstract}
A B S T R A C T
Background: Standard Precaution (SPs) practices protect health-care workers prevent hospital-acquired infections. With Competency Based Medical Education (CBME) and early clinical exposure (ECE) implemented in the new curriculum, the first year medical students need to be aware of SPs, so as to protect themselves and the patients from these hazards.

Aims \& objective: To assess the knowledge of standard precautions among the medical students and find out association of knowledge with selected demographic variables.

Methods and material: This cross-sectional study was done among first year medical undergraduate students of a medical college.Data was collected through google form with researcher-made questionnaire including questions on knowledge about SPs and socio-demographic variables of the study participant and their parents.

Results: Response rate was $97.9 \%$. Mean age of the participants was $19.13 \pm 0.858$ years; $57.7 \%$ were girls. Although $80.3 \%$ had heard of SPs but as high as $83.1 \%$ were of the opinion that "SPs were only for protection of the health-care team", $23.2 \%$ felt that it should "only be used in patients diagnosed with infection". $96.5 \%$ knew that "hand hygiene should be performed while providing care to patients", $97.2 \%$ had knowledge about respiratory and cough hygiene practices, $14.1 \%$ of them felt that "PPE can be shared". $57 \%$ of the respondents answered that "needle should be recapped after giving injections".

Conclusions: Students in early clinical years were found to have a varied level of knowledge of SPs and a lot of gaps in correct understanding of required facts. Continued medical education and skill-assessment to test their knowledge, must be incorporated into their teaching curriculum before ECE, so as to minimize the risk of preventable infections.
\end{abstract}

\section{Introduction}

As defined by CDC,Standard Precautions(SPs) are the minimum infection prevention practices that apply to all patient care, regardless of suspected or confirmed infection status of the patient, in any setting where health care is delivered. SPs practices include - hand hygiene, use of personal protective equipment(PPE), respiratory hygiene, sharps safety, safe injection practices, sterile instruments and devices, clean and disinfected environmental surfaces. ${ }^{1}$

Hand hygiene is a major component of SPs and is one of the most effective methods to prevent transmission of Hospital Acquired Infections(HAIs). In addition to practices carried out by health-care workers(HCWs), all individuals (including patients and visitors) should comply with infection control practices to control spread of pathogens from the source. ${ }^{2}$ Among source control measures, cough etiquette/respiratory hygiene, is now gaining importance amidst the current evolving pandemic of COVID-19. ${ }^{12}$
Some of the main sources of exposure to HCWs are needle-stick injury, touching own eyes, nose, mouth, or open skin after touching or handling contaminated materials, droplet infection. ${ }^{3}$ Compliance and adherence to SPs practices protect HCWs including medical students from percutaneous injuries and prevent HAIs. Limited exposure of the medical undergraduates in performing invasive procedures in early clinical years, particularly puts in higher risk of acquiring nosocomial infections. $^{4}$

Competency based Medical Education(CBME)is an approach to ensure that the graduates develop the competencies required to fulfill the patients' needs in the society and emphasize more on skill based learning. It de-emphasizes time-based training and promises greater accountability, flexibility, and learner-centeredness.

With CBME and early clinical exposure (ECE) in the new curriculum, the first-year medical students need to be aware of SPs, so as to protect themselves and the patients from these hazard before they are exposed to the clinical wards. Assessing knowledge of the medical

\footnotetext{
* Corresponding author. Department of Community Medicine, Kalinga Institute of Medical Sciences, KIIT University, Bhubaneswar, Odisha, 751024, India.

E-mail address: dr_ipsa@yahoo.co.in (M. Ipsa).
} 
undergraduates towards SPs will help in bringing in reforms and measures necessary to develop better knowledge, compliance,skill and clinical acumen in students later on during real clinical practice ${ }^{4}$ help prevent HAIs by them.

\subsection{Aim \& objectives}

SPs has been researched in varied Health Care Provider(HCP) groups, but is not much researched yet in medical students. Keeping this in view and the need due to ECE with CBME in the new curriculum, this study was taken up with the following objectives:

1. To assess the knowledge of standard precautions among the medical students

2. To find out the association of knowledge of Standard Precaution with selected demographic variables like - parental education, occupation

\section{Materials and methods}

Study Design: Cross-Sectional Study.

Study Period: Total study period was of one month (June 2020) including data collection.

Study Setting: Study was carried out in a Medical College situated in Bhubaneswar, Odisha.

Study Population: Were the first year medical undergraduate students of the medical college who joined in the year 2019.

Inclusion criteria: All first year medical students of 2019 admitted batch giving written informed consent(A Disclaimer stating "The information on knowledge about Standard Precautions will help to adopt the correct measures of precautions in clinical practice.This study will take around 20-30 min. All the answers and your identity will be confidential and used for research purpose only.Your participation in the study is voluntary.With the filling of the study questionnaire,we understand that you are providing consent to participate" was added in the google form prior to answering the questionnaire).

Exclusion criteria: Students absent on the date of data collection.

\subsection{Sample size}

All 150 students were invited to participate in the study, but on the day of data collection, 5 students were absent and 3 students out of the 145 students who were present,submitted incomplete-questionnaire (google form), hence were excluded from the study, making a final sample size of 142 .

Sampling technique: convenience sampling.

\subsection{Study instrument}

Google form with semi structured, pre-designed, pretested researcher-made self-administered questionnaire developed after a through review of literature on $\operatorname{SPs}^{1-3,6}$ including 18 questions on knowledge about SPs containing closed ended questions(with options yes/no); the questions had the following sections:

1. Socio-demographic details of the participants and their parents education and occupation was considered. For education and occupation we used modified kuppuswamy scale.For data analysis, parental occupation was categorised as medical professional and non medical professional, where we found that those categorised as medical professional were all doctors.

2. Knowledge about SPs including definition and all the domains of SPs such as hand hygiene, use of personal protective equipment, respiratory hygiene, sharps safety, safe injection practices, sterile instruments and devices, clean and disinfected environmental surfaces

\section{Ethical approval}

The study was approved by the institutional Ethics committee vide letter no.KIIT/KIMS/IEC/289/2020 dated.

\section{Data collection}

\subsection{Methodology of data collection}

As per the new curriculum, the students were earlier taught regarding universal precautions in the month of September 2019; thus students had a basic idea of the same. During the online classes the students were first briefed about the purpose of the study and how it was essential for them, to have a proper knowledge and develop skills about the various precautionary measures recommended and practiced in hospital setting, which would prevent them from various HAIs and their support was sought. After their consent, the investigator conducted a data collection session, wherein students were sent the google form with questionnaire to complete it within a stipulated time (30 $\mathrm{min})$. Confidentiality of all participants was maintained. At the end of the session, on the same day students were given video lectures regarding the correct SPs practices, wherein video demonstration ${ }^{13-16}$ of each component like hand hygiene, respiratory etiquette etc was shown and students were encouraged to do the same. Any query raised by the students was also answered.

\subsection{Data analysis}

All google forms submitted were checked for completeness at the end of data collection. Data was exported from the google form into Microsoft excel 2007 spreadsheet and analysed using Epi info software [LANGUAGE en-US version 7.2.3.1]. For categorical variables, frequencies and percentages were used. For continuous variables mean \& standard deviation. To find out the association between categorical variables the chi-square or fisher exact test were used where appropriate. A level of 0.05 was considered as statistically significant.

\section{Results}

All the consenting students, who submitted complete answer schedule(142) on the day of data collection were taken. $97.9 \%$ was found to be the response rate, wherein 142 students out of 145 present completed the questionnaire.Students and their parental sociodemographic characteristics are presented in Table 1. Findings show that $57.7 \%$ of the students were females and the majority were in the age group of 17-19 years. The mean age of the study participants was 19.13 \pm 0.858 years(Range:17-22). 49\%(70) of the student's fathers were in age group 51-60 years and 76\%(108) of the student's mothers were in age group 41-50 years. Mean age of the fathers' was found to be $51.51 \pm$ 4.561 years(Range:41-65) as compared to $46.71 \pm 4.249$ years (Range:38-56) of the mothers'.16.2\%(23) of fathers and $7.1 \%{ }^{10}$ of the mothers were doctors by profession. Majority of the students were Hindus (92.2\%) and all belonged to Upper class(according to modified Kuppuswamy classification 2019).

Out of the 142 students,114(80.3\%) had answered that they had heard about SPs prior. Fig. 1 shows the various source of information regarding, the same, as answered by the students. 62(54\%) revealed the source to be formal teaching in medical school, followed by knowledge from parents or family members (22\%) and colleagues/friends (13\%).

Knowledge regarding the components of SPs among students is presented in details in Table $2.76 .8 \%$ had correct knowledge of the definition of SPs, but $83.1 \%$ were of the opinion that "SPs were only for protection of the health-care team", $23.2 \%$ felt that it should "only be used in patients diagnosed with infection". 96.5\% knew that "hand hygiene should be performed while providing care to patients", $97.2 \%$ had knowledge about respiratory and cough hygiene practices, $57 \%$ of 
Table 1

Sociodemographic details of study participants and their parents $(\mathrm{N}=142)$.

\begin{tabular}{|c|c|c|}
\hline Variables & $\mathrm{N}$ & $\begin{array}{l}\text { Percent of } \\
\text { total }\end{array}$ \\
\hline \multicolumn{3}{|l|}{ Gender } \\
\hline Male & 60 & 42.3 \\
\hline Female & 82 & 57.7 \\
\hline \multicolumn{3}{|l|}{ Age of the Participants(in years) } \\
\hline $17-19$ & 97 & 68.3 \\
\hline $20-21$ & 44 & 31 \\
\hline$\geq 22$ & 1 & 0.7 \\
\hline \multicolumn{3}{|l|}{ Age of Father(in years) } \\
\hline $41-50$ & 68 & 48 \\
\hline $51-60$ & 70 & 49 \\
\hline$\geq 61$ & 4 & 3 \\
\hline \multicolumn{3}{|l|}{ Education of Father } \\
\hline Upto Senior Secondary(12th) & 3 & 2.2 \\
\hline Graduate(B.A/B. tech/MBBS/LLB/B.Sc etc) & 83 & 58.4 \\
\hline $\begin{array}{l}\text { Post graduate and beyond (MD/MS/M.A./M. tech/LLM/ } \\
\text { PhD etc) }\end{array}$ & 56 & 39.4 \\
\hline \multicolumn{3}{|l|}{ Occupation of Father } \\
\hline Doctor/Medical Professional & 23 & 16.2 \\
\hline Self Employed(Business/NGO) & 51 & 36 \\
\hline Service(Govt. sector/Private sector) & 68 & 47.8 \\
\hline \multicolumn{3}{|l|}{ Age of Mother(in years) } \\
\hline $31-40$ & 11 & 8 \\
\hline $41-50$ & 108 & 76 \\
\hline$\geq 51$ & 23 & 16 \\
\hline \multicolumn{3}{|l|}{ Education of Mother } \\
\hline Upto Senior Secondary(12th) & 10 & 7 \\
\hline Graduate(B.A/B. tech/MBBS/LLB/B.Sc etc) & 82 & 58 \\
\hline $\begin{array}{l}\text { Post graduate and beyond (MD/MS/M.A./M. tech/LLM/ } \\
\text { PhD etc) }\end{array}$ & 50 & 35 \\
\hline \multicolumn{3}{|l|}{ Occupation of Mother } \\
\hline Doctor/Medical Professional & 10 & 7 \\
\hline Service(Govt. sector/Private sector)) & 39 & 27.5 \\
\hline Unemployed(Housewife) & 93 & 65.5 \\
\hline
\end{tabular}

the respondents answered that "needle should be recapped after giving injections".

Hand hygiene knowledge of the beginners in the medical field is one of the most important measure in controlling nosocomial infections (Fig. 2).

Fig. 3 shows the response to the question on what all PPE should be used, when there is a possibility of exposure to blood/body fluid/secretions/excretions. $65.5 \%(93)$ agreed that all 4 types are PPE are to used, $4.6 \%$ knew that "contact with objects, materials, equipment, clothing and individuals with contaminated PPE should be avoided" and 85.9\% agreed that PPE should not be shared.

With regard to the knowledge about SPs among students, association was established with parental education and occupation (Table 3). Children of medical professionals and those whose parents who had higher education (post-graduation and above),were found to have better knowledge regarding SPs as compared to their counterparts; this difference was not found to be statistically significant.

\section{Discussion}

This study was done among 142 first year medical undergraduate students of a private medical college to assess their knowledge on standard precautions. The mean age of the students was $19.13 \pm 0.858$ years, majority were Hindus and all belonged to upper class (according to modified Kuppuswami classification 2019). 16.2\% of the fathers and $7.1 \%$ of the mothers were medical professionals.

In this study, $80.3 \%$ had answered that they had heard about SPs as compared to $53.5 \%$ medical students had heard about it in a study done by N.Motamed et al. ${ }^{7}$ and $33.6 \%$ medical students in clinical years had heard as shown in a study by Karim et al. in Kuwait university. ${ }^{8}$ Whereas study done by Solanki et al. among nursing staff,showed $100 \%$ of participants had heard before. ${ }^{9}$ This difference can be due to the earlier exposure of the nursing students as compared to medical students to real clinical practice.

$54 \%$ of the study participants opined that formal teaching in medical school was their source of knowledge, but in a similar study among Saudi University students by Tarek Tawfik Amin et al., though medical curriculum was reported as the main source of their general knowledge

Table 2

Knowledge regarding the components of Standard Precautions(SPs)(N = 142).

\begin{tabular}{|c|c|}
\hline Knowledge about standard precautions $(\mathrm{N}=142)$ & $\begin{array}{l}\text { Correct answer } \\
\text { frequency(\%) }\end{array}$ \\
\hline Correct knowledge of Standard precaution definition & $109(76.8)$ \\
\hline Only protects health care team $(\mathrm{N})$ & $24(16.9)$ \\
\hline $\begin{array}{l}\text { Cover their nose and mouth when coughing/sneezing with } \\
\text { tissue or mask (Y) }\end{array}$ & $138(97.2)$ \\
\hline $\begin{array}{l}\text { Perform hand washing after contact with respiratory } \\
\text { secretions }(\mathrm{Y})\end{array}$ & 139(97.9) \\
\hline $\begin{array}{l}\text { Disinfection of environmental and other frequently touched } \\
\text { surfaces should be done (Y) }\end{array}$ & $127(89.4)$ \\
\hline $\begin{array}{l}\text { Should we treat waste contaminated with body fluids/blood } \\
\text { as clinical waste (Y) }\end{array}$ & $83(58.5)$ \\
\hline $\begin{array}{l}\text { Clean reusable equipment appropriately before use with } \\
\text { another patient }(\mathrm{Y})\end{array}$ & 128(90.1) \\
\hline $\begin{array}{l}\text { Is recapping of needles after giving injections a good } \\
\text { practice }(\mathrm{Y})\end{array}$ & $81(57)$ \\
\hline
\end{tabular}

Correct response: $\mathrm{Y}=\mathrm{Yes} ; \mathrm{N}=$ No.

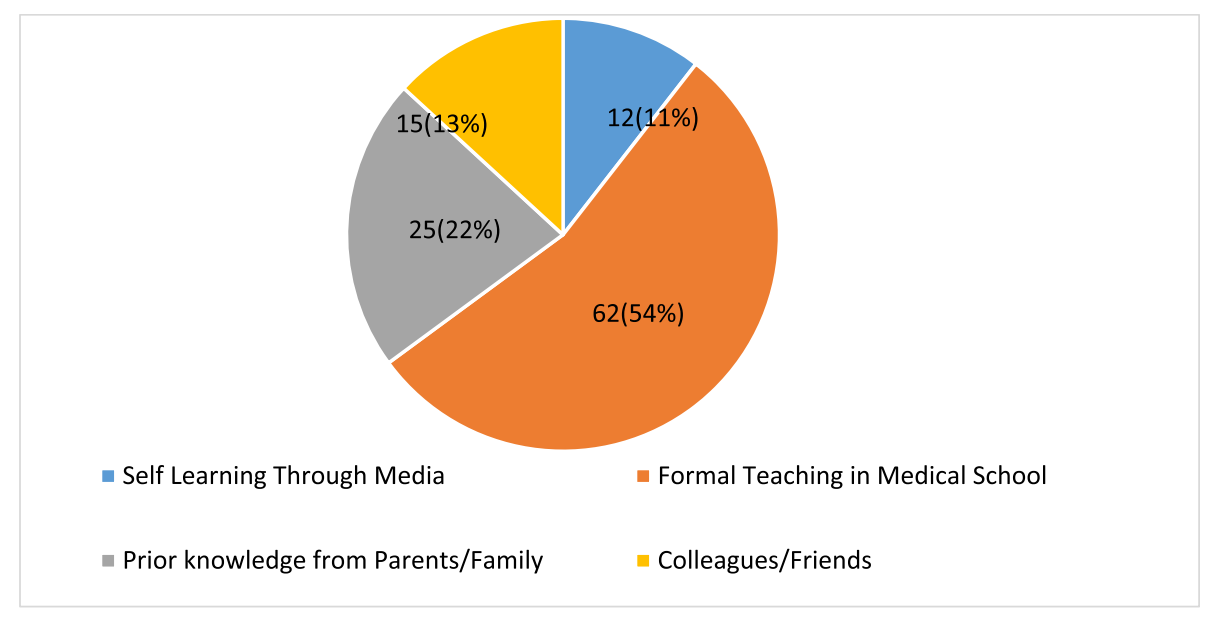

Fig. 1. Source of information about Standard precaution( $\mathrm{n}=114 \#)$.

\# only 114 had heard about Standard precautions prior 


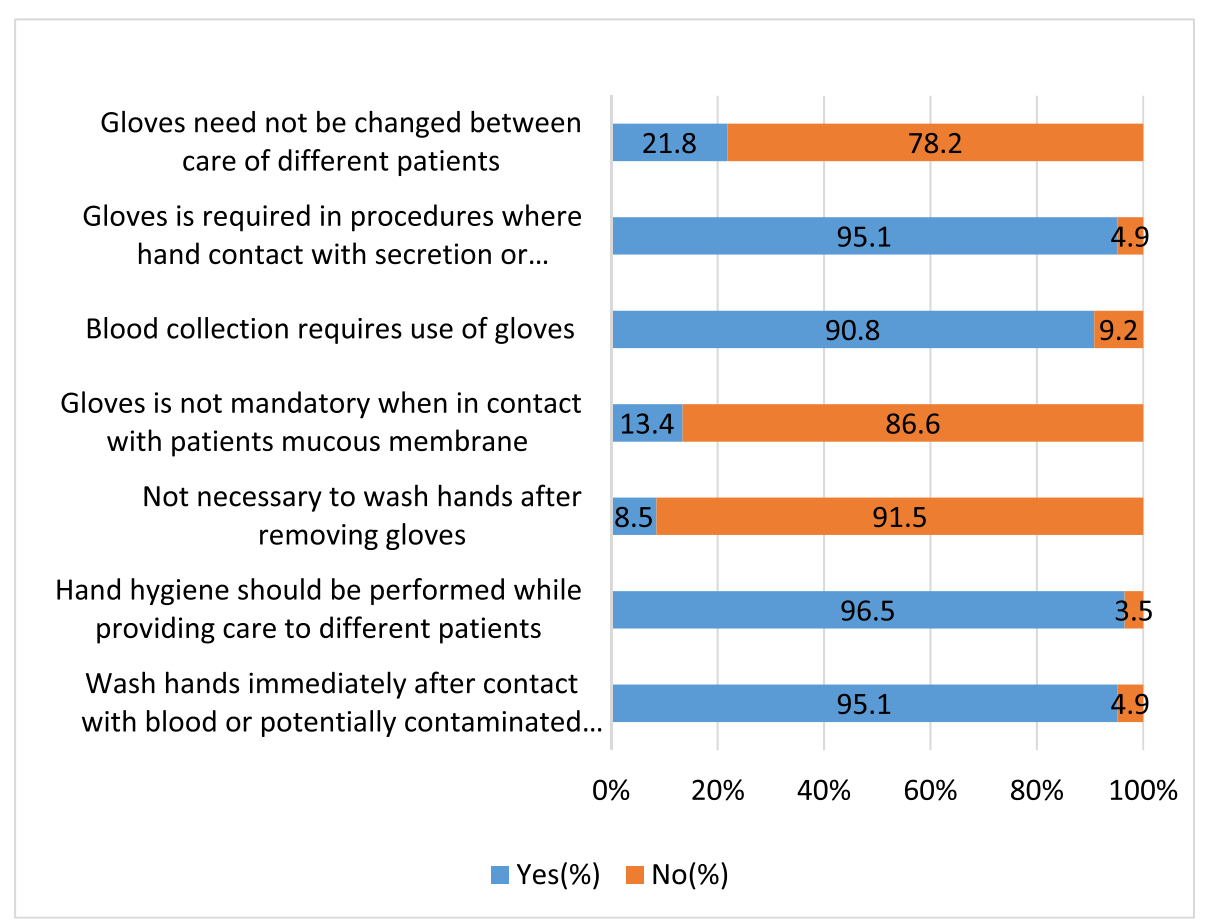

Fig. 2. Knowledge on various precaution measures of hand hygiene.

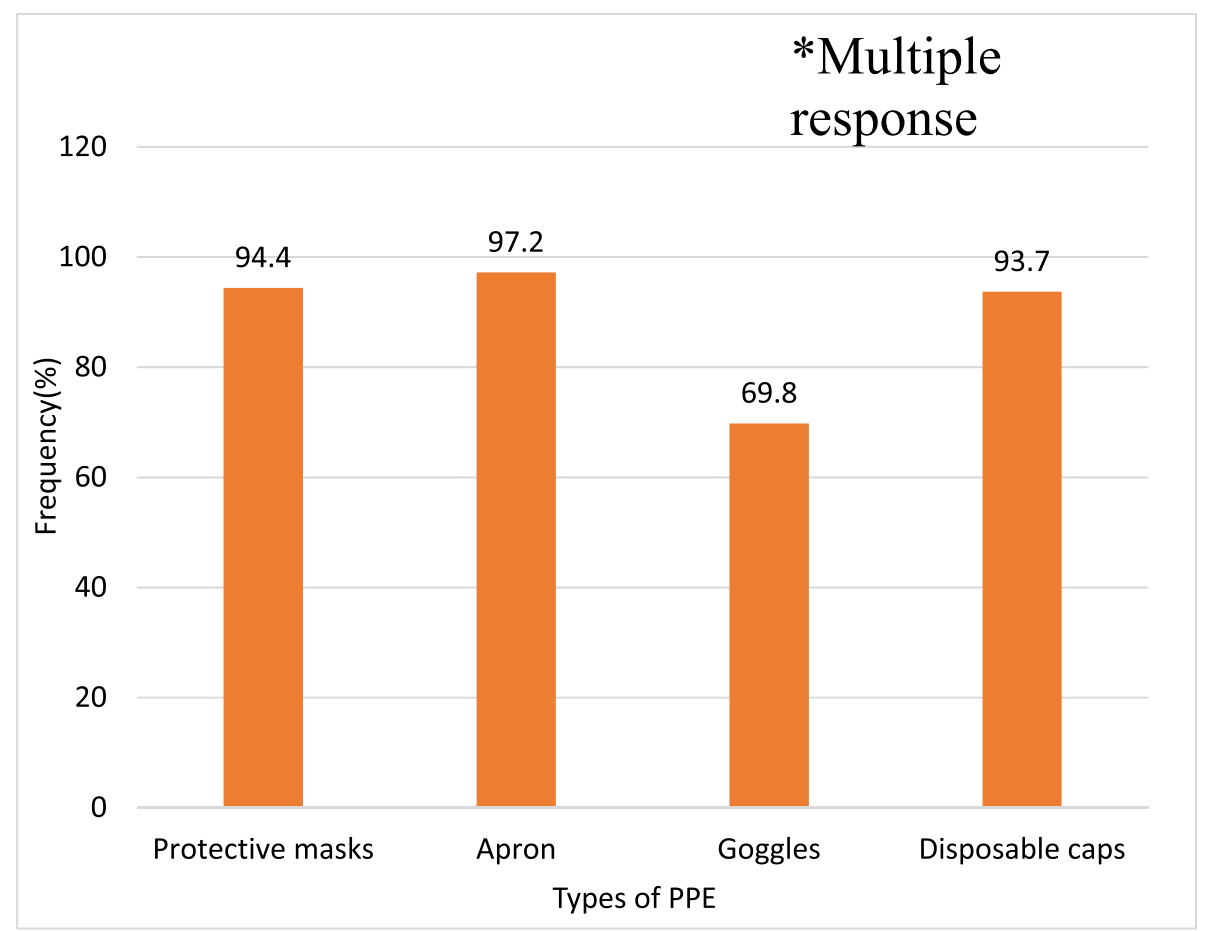

Fig. 3. Response to what all PPE should be used when there is a possibility of exposure to blood/body fluid/secretions/excretions*.

about SPs except for the PPE and sharps management domain, bed side practices was reported as the main source of knowledge ${ }^{4}$ Introduction of the new skill and competency based curriculum along with awareness drives in various media might be the reason to upgrade the residual knowledge of the students posing them for better compliance and acumen in real practice.

In the present study, $16.9 \%$ knew SPs not only protects the health care team but also protects the patients as well.76.8\% students answered that SPs measures should be adopted regardless of the infection status of patients as compared to $90.9 \%$ medical students agreed to the same fact in the study done by N.Motamed et al. ${ }^{7}$ The overall knowledge for SPs in the study participants were good in the domains of hand hygiene, respiratory hygiene, sharp management, personal protective equipment as compared to the results shown in the study done in Saudi University ${ }^{4}$ in the year 2013.Knowledge on hand hygiene practices amongst the medical students was good as $96.5 \%$ knew hand hygiene to be performed while providing care to patients and $95.1 \%$ agreed they should wash hands immediately after contact with potentially contaminated 
Table 3

Association of knowledge of Standard Precautions with parental details.

\begin{tabular}{|c|c|c|c|}
\hline \multirow[t]{2}{*}{ Demographic variables of the parents } & \multicolumn{2}{|c|}{$\begin{array}{l}\text { Knowledge on standard } \\
\text { precautions }\end{array}$} & \multirow[t]{2}{*}{$P$ value } \\
\hline & Yes(n = 114) & No(n = 28) & \\
\hline Fathers education & & & 0.27 \\
\hline Upto Graduation(86) & $66(76.8)$ & $20(23.2)$ & \\
\hline Post Graduate and beyond(56) & $48(85.8)$ & $8(14.2)$ & \\
\hline Fathers occupation & & & 1 \\
\hline Medical professional(23) & $19(82.6)$ & $4(17.4)$ & \\
\hline Non Medical Professional(119) & $95(79.8)$ & $24(20.2)$ & \\
\hline Mothers education & & & 0.47 \\
\hline Upto graduation(92) & $76(82.6)$ & $16(17.4)$ & \\
\hline Post graduate and beyond(50) & $38(76)$ & $12(24)$ & \\
\hline Mothers Occupation & & & 0.69 \\
\hline Medical professional(10) & $8(80)$ & $2(20)$ & \\
\hline Non Medical Professional(132) & $106(80.3)$ & $26(19.7)$ & \\
\hline
\end{tabular}

fluid or material whereas while conducting a comparative evaluation of the level of knowledge and practice among nursing and medical students by Garcia Zapata et al. in Brazil their study ascertained that $100 \%$ of the nursing student and $91 \%$ of the medical students knew that their hands had to be washed before and after patient care. However, compliance in practice was noted in $26.9 \%$ of the nursing students and $2.6 \%$ of the medical students. ${ }^{10}$ With CBME and ECE, medical students also need to have practice and training sessions to develop appropriate skills along with knowledge. Correct knowledge regarding handling and disposal of needle sticks and other sharp objects among medical students was found to be $57 \%$ compared to $42.3 \%$ in the study by Garcia Zapata et al. ${ }^{10}$ Only $69.8 \%$ of the study participants responded that goggles/face shield are to be used as PPE while handling contaminated materials/patients along with gloves, apron and caps, which showed inadequate knowledge among students.

No statistical significant difference was found amongst association of parental education and occupation with knowledge of SPs among students, but findings showed children of parents with higher educational background and children of medical professionals had better residual knowledge, which might be due to better knowledge regarding basic hygiene practices and also complying to those practices in the home environment as well. As noted barriers to comply with standard infection control protocol in a study among hospital support staff by Jha A T et al. showed, $40 \%$ of the respondents were educated only up to primary level or were illiterates, ${ }^{11}$ so level of education can be an important factor, regarding compliance.

The strengths of the study are it was first of its kind being done among first year students after introduction of CBME and ECE in the new curriculum.

\section{Conclusion}

This study aimed to assess the knowledge of SPs in detail among the first year medical undergraduate students.Students in these early clinical years were found to have a varied level of knowledge about the Standard Precaution measures; lot of gaps were found in correct understanding of required facts.Although parents education and occupation was not found to be statistically significant but it were found that children of parents in medical profession had better residual knowledge compared to those whose parents were in some other profession.

\subsection{Recommendation}

Continued medical education and skill-assessment to test their knowledge, must be incorporated into their teaching curriculum before ECE, so as to minimize the risk of preventable infections amongst these group of students. Future research can be planned with objective to assess and compare the knowledge of students prior and later to application of CBME curriculum.

\subsection{Limitation of the study}

The limitation of the study being, the study was done only for first year students, hence variations in the overall knowledge of medical students in higher semesters may be there. Being a cross-sectional study, it limits its ability to draw a causal relationship. Lastly, being a selfreported study, there may be instances of reporting bias.

\subsection{Relevance of the study}

This study was an attempt to assess the level of knowledge of SPs of students in their early clinical years. It also assessed the sociodemographic variables of parents influencing their knowledge. Findings based on this study will provide evidence that continued medical education and skill assessment to test their level of knowledge, incorporated into their teaching curriculum before clinical exposure, will help them develop better clinical acumen.

\section{Funding source}

Nil.

\section{Acknowledgement}

We would like to acknowledge all the participants of the study,and the class representatives for facilitating one of the Self directed learning (SDL) classes for data collection and video demonstration.

\section{References}

1 CDC:StandardPrecaution. available from: https://www.cdc.gov/oralhealth/infecti oncontrol/summary-infection-prevention-practices/standard-precautions.html.

2 WHO:standard-precautions-in-health-care. from https://www.who.int/docs/default -source/documents/health-topics/standard-precautions-in-health-care.pdf?sfvrsn=7 c453df0_2.

3 CDC,Niosh Publications. Caring for yourself while caring for others. from htt ps://www.cdc.gov/niosh/docs/2015-102/pdfs/F14_Handout_4_2015-102.pdf.

4 Amin TT, Al Noaim KI, Bu Saad MA, Al Malhm TA, Al Mulhim AA, Al Awas MA. Standard precautions and infection control, medical students' knowledge and behavior at a Saudi university: the need for change. Global J Health Sci. 2013;5(4): 114-125. https://doi.org/10.5539/gjhs.v5n4p114. Published 2013 Apr 21.

5 Shah N, Desai C, Jorwekar G, Badyal D, Singh T. Competency-based medical education: an overview and application in pharmacology. Indian J Pharmacol. 2016; 48(Suppl 1):S5-S9. https://doi.org/10.4103/0253-7613.193312.

6 Valim Marília Duarte, Pinto Priscila Aparecida, Marziale Maria Helena Palucci. Questionnaire ON standard precaution knowledge: validation study for BRAZILIAN nurses use [Internet] Texto contexto - enferm. 2017;26(3), e1190016. https://doi.org/ 10.1590/0104-07072017001190016 [cited 2020 June 27] http://www.scielo.br /scielo.php?script=sci_arttext\&pid=S0104-07072017000300324\&lng=en. Accessed September 21, 2017. Available from:.

7 Motamed N, BabaMahmoodi F, Khalilian A, Peykanheirati M, Nozari M. Knowledge and practices of health care workers and medical students towards universal precautions in hospitals in Mazandaran Province. East Mediterr Health J Rev Sante Mediterr Orient Al-Majallah Al-Sihhiyah Li-Sharq Al-Mutawassit. 2006;12(5):653-661. Sep.

8 Karim J, Al-Saraji M, Al-Mousawi F, et al. Knowledge and self-reported practice of universal precautions among Kuwait University medical students in their clinical years. Med Princ Pract. 2012;21(4):328-333. https://doi.org/10.1159/000335278. Epub 2012 Jan 13. PMID: 22248907.

9 Solanky P, Baria H, Nerulkar A, Chavda N. Knowledge and practice of universal precautions among nursing staff at a tertiary care hospital in South Gujarat, India. Int J Community Med Public Health. 2016;3:2373-2376.

10 Rocha-Carneiro García-Zapata Mary, Souza Adenícia Custódia Silva e, Guimarães Janaína Valadares, Tipple Anaclara Ferreira Veiga, Prado Marinésia Aparecida, García-Zapata Marco Tulio Antonio. Standard precautions: knowledge and practice among nursing and medical students in a teaching hospital in Brazil. Int J Integrated Care; 2020 [Internet]. [cited july 92020 ]. Available from: https://www. ijic.info/article/view/4075.

11 Jha AT, Jacob GP, Ramireddy M, Kini YK. Awareness and practices regarding standard precautions for infection control among the hospital support staff in a tertiary care hospital in South India: a cross sectional study. Int J Community Med Public Health. 2017;4:2690-2695. 
12 WHO.Coronavirus disease (COVID-19) advice for the public; 2020. From https://www who.int/emergencies/diseases/novel-coronavirus-2019/advice-for-public. Accessed June 4, 2020

13 WHO.WHO: how to handwash? With soap and water; 2015 [video on the Internet]. 2015 October20. Available from: https://www.youtube.com/watch?v=3P MVJQUCm4E.

14 AIIMS New Delhi.social cough etiquette - English; 2020 [video on the Internet]. 2020 April 1. Available from: https://www.youtube.com/watch?v=25JgKnnRatw.
15 CDC. Demonstration of donning (putting on) personal protective equipment (PPE); 2020 [video on the Internet].2020 April 21.Available from: https://www.youtube.com/w atch? $\mathrm{v}=$ of73FN086E8.

16 CDC. Demonstration of doffing (putting off) personal protective equipment (PPE); 2020 [video on the Internet].2020April 21. Available from: https://www.youtube.com/w atch? $\mathrm{v}=\mathrm{PQxOc} 13 \mathrm{DxvQ}$. 